\title{
25 Research Soure \\ Cost-Effectiveness Analysis of A Quality Improvement Program to Reduce Cesarean Sections in Brazilian Private Hospitals: A Case Study
}

Rosa Maria Soares Madeira Domingues ( $\sim$ rosamsmd@gmail.com )

Fundacao Oswaldo Cruz https://orcid.org/0000-0001-5722-8127

Paula Mendes Luz

Fundação Oswaldo Cruz: Fundacao Oswaldo Cruz

Bárbara Vasques da Silva Ayres

Fundacao Oswaldo Cruz

Jacqueline Alves Torres

ANS: Agencia Nacional de Saude Suplementar

Maria do Carmo Leal

Fundação Oswaldo Cruz: Fundacao Oswaldo Cruz

\section{Research}

Keywords: cesarean delivery, healthcare quality improvement, hospitals medicine, Cost-effectiveness

Posted Date: September 3rd, 2020

DOI: https://doi.org/10.21203/rs.3.rs-67630/v1

License: (c) (i) This work is licensed under a Creative Commons Attribution 4.0 International License. Read Full License 


\section{Abstract}

Background: In 2015, a quality improvement project of childbirth care called Adequate Birth Project ("Projeto Parto Adequado"- PPA) was implemented in Brazilian public and private hospitals, aiming to improve the quality of childbirth care and to reduce cesarean sections without clinical indications. The objective of this study is to conduct an economic analysis of two models of care existing in a private Brazilian hospital - the model following the recommendations of the PPA and the standard of care model - in reducing the proportion of cesarean sections.

Methods: We conducted a case study in one of the private hospitals included in the PPA project. The main outcome was the proportion of cesarean section. We used total cost of hospitalization for women and newborns, from the perspective of the health care provider, during the length of the observed hospital stay. We did not apply discount rates and inflation rate adjustments due to the short time horizon. We conducted univariate sensitivity analysis using the minimum and maximum costs observed in hospitalizations and variation in the probabilities of cesarean section and of maternal and neonatal complications.

Results: 238 puerperal women were included in this analysis. The PPA model of care resulted in a 56.9 percentage point reduction in the cesarean section probability ( $88.6 \%$ vs $31.7 \%, p<0.001)$ and an increase in the total cost of US\$ $67,346.25$, which an incremental cost-effectiveness ratio of US\$ $1,183.59$ per avoided cesarean section. Women in the PPA model of care also had a higher proportion of spontaneous and induced labor and a lower proportion of early term births. There were no maternal, fetal or neonatal deaths and no significant differences in cases of maternal and neonatal nearmiss. The cost of uncomplicated vaginal births and cesarean sections was the parameter with the greatest impact on the cost-effectiveness ratio of the PPA model of care.

Conclusion: The quality improvement project of childbirth care "PPA" was cost-effective in reducing cesarean sections in women assisted in a Brazilian private hospital, without increasing severe negative maternal and neonatal outcomes and reducing the frequency of early term births.

\section{Introduction}

Caesarean section is a safe intervention to save the lives of women and newborns. However, it is associated with negative short, medium and long-term health consequences for women and children ${ }^{1-5}$. Therefore, its harmful effects can outweigh its benefits when used excessively. At the population level, there is no evidence that cesarean rates above $10 \%$ are associated with a reduction in the maternal mortality ratio ${ }^{6}$, although population characteristics may affect cesarean rates in each country ${ }^{7}$. In Brazil, considering demographic and obstetric characteristics for Brazilian women, the expected rate of cesarean delivery for the country would be 25 to $30 \%{ }^{8}$. For women admitted to private hospitals, this value would be $44.4 \%$.

Since 2009, cesarean section is the most frequent type of birth in the country. Cesarean section is associated with demographic, socioeconomic factors and the type of childbirth care services organization. In Brazilian private hospitals, cesarean section rates reach $90 \% 9,10$.

In 2015, the National Supplementary Health Agency (ANS), responsible for regulating the supplementary health sector in the country, together with the Institute for Health Improvement $(\mathrm{IHI})$ and Hospital Israelita Alberto Einstein, and with the support of the Brazilian Ministry of Health, implemented the Adequate Childbirth Project ("Projeto Parto AdequadoPPA"). This is a quality improvement project of childbirth care in Brazilian hospitals that aims to identify innovative and viable models of care, which value vaginal delivery and reduce the percentage of cesarean sections without clinical indication ${ }^{11,12}$. 
The objective of this study is an economic analysis of two models of care existing in a private Brazilian hospital - the model following the recommendations of the PPA and the standard of care model - in reducing the proportion of cesarean sections.

\section{Methods}

\section{Study design}

This is an economic analysis of the model of care implemented from the PPA to reduce cesarean sections in a private Brazilian hospital.

The PPA is a quality improvement project of childbirth care implemented in Brazilian public and private hospitals, with the goal of increasing the percentage of vaginal deliveries and reducing the rate of hospitalization in a neonatal intensive care unit (NICU) ${ }^{11-13}$. It is an ongoing project, started in May 2015 and developed in three phases described in Fig. 1. More information about the PPA is available at the ANS website ${ }^{11}$ and at Boren et al ${ }^{12}$.

In 2017, an evaluative research called the "Healthy Birth" study was carried out to assess the degree of implementation and the effects of the PPA in a convenience sample of 12 hospitals, among the 23 private hospitals that participated in the first phase of the project ${ }^{14}$. Sample calculation used as parameters a $50 \%$ prevalence of cesarean section and a power of $80 \%$ to detect a $10 \%$ reduction in the cesarean rate with a significance level of $5 \%$ resulting in a minimum sample of 400 women in each hospital.

Women with live births of any weight or gestational age and stillbirths weighing $500 \mathrm{~g}$ or more or with 22 or more gestational weeks were eligible for the "Healthy Birth" study. Exclusions included home births or public deliveries, women who did not speak Portuguese, with hearing loss, and with legal determination to terminate pregnancy.

All women admitted for childbirth care and who met the eligibility criteria were invited to participate in the study, until 400 participants were included in each hospital. Face-to-face interviews with puerperal women were conducted at least 6 hours after vaginal delivery and 12 hours after a cesarean section. Hospital records were reviewed and data were extracted after hospital discharge. Data collection was carried out from March 2017 to August 2017, 6 to 8 months after the end of the first phase of the PPA (Fig. 1). More information about the "Healthy Birth" study is available in Torres et al 14

For this economic analysis, we carried out a case study in one of the hospitals included in the "Healthy Birth" study, the only hospital that made available the hospitalization costs of the 400 women included in the study. This hospital is located in the southeastern region of the country and belongs to a private health insurance provider. Figure 1 summarizes the information from the PPA, the "Healthy Birth" study and this economic analysis.

Figure 1: Description of the "Adequate Childbirth Project", the evaluative research "Healthy Birth "and the economic analysis study

\section{Comparative models of care: PPA model of care and standard of care model}

The PPA project aims to support and promote the implementation of actions to reduce the percentage of unnecessary cesarean sections and increase the quality and safety of care during labor and birth. It is a multifaceted intervention, with activities that are structured in four theoretical components: 1) Governance (coalition between leaders aiming at quality and safety in childbirth care); 2) Women and families (empowerment of women and their families aiming at their 
active participation in the process of pregnancy, childbirth and postpartum); 3) Reorganization of care (reorganization of care in order to favor the physiological evolution of labor and the performance of cesarean sections based on clinical factors); 4) Monitoring (structuring information systems for continuous learning). The activities provided for in the four components are based on scientific evidence ${ }^{15}$ and on 2 successful strategies for reducing cesarean sections in Brazilian private hospitals ${ }^{16,17}$.

The PPA uses the $\mathrm{IHI}$ improvement model, where through the cyclical and incremental implementation of changes, the proposed activities are tested and adjusted to the local context, allowing their implementation and refinement ${ }^{13}$. In the first phase of the project, managers and local leaders participated in five face-to-face learning sessions in addition to monthly virtual learning sessions, focusing on training in the improvement model, initial tests of change to reduce the cesarean rate based on the four PPA components and sharing successful experiences and challenges in implementing changes. In addition, the project offered clinical training at realistic simulation centers, with a focus on assisting physiological vaginal delivery and managing obstetric complications ${ }^{12}$.

At the hospital level, the project implemented new forms of care organization, with changes in the hospital environment, access to non-pharmacological methods for pain relief and equipment for births in vertical positions. Hospital staff included nurse-midwives in childbirth care and trained professionals implemented clinical guidelines. Activities for women aimed at greater autonomy and involvement of pregnant women in the decision-making process related to childbirth, through access to information, participation in educational groups, encouragement to develop a birth plan and visit to the hospital.

In Brazilian private hospitals, women assisted in the standard of care model are usually seen by the same doctor during prenatal and childbirth care ${ }^{16}$. There is low participation of nurse-midwives ${ }^{18}$, a high proportion of antepartum cesarean Sect. ${ }^{10}$, low use of labor induction ${ }^{10}$, low use of best practices and high use of obstetric interventions during labor ${ }^{19}$.

\section{Study population}

In this case study, we restricted the analysis to women in the Robson's groups 1 to 4 , the current target population of PPA. Robson's classification classifies women into 10 mutually exclusive groups based on the type of pregnancy, parity, fetal presentation, gestational age and in the presence of a previous cesarean Sect. ${ }^{20}$. Groups 1 to 4 correspond to primiparous and multiparous women, with single, full-term pregnancies, with a fetus in cephalic presentation and without previous cesarean section. Groups 2 and 4 can also be subdivided into groups $2 a$ and $2 b$ and $4 a$ and $4 b$, with groups "a" represented by women with labor induction and groups "b" by women with antepartum caesarean Sect. ${ }^{21}$.

We also excluded women with diagnosis of HIV infection and newborns with congenital malformations or with gestational age equal to or greater than 42 weeks, due to the greater possibility of cesarean sections and negative outcomes. As we used the perspective of the health care provider, we also excluded women with out of pocket payment for childbirth care.

In this hospital, all women assisted by the hospital team on duty were followed according to the PPA model of care. Using data obtained during the interview, we classified women as "PPA model of care", if they reported being assisted by the hospital team on duty, and as "standard of care model", if they were assisted by an external staff.

\section{Effectiveness}

We used the primary outcome "proportion of cesarean section", including antepartum and intrapartum cesarean sections, obtained from hospital records, to measure effectiveness. In addition to the crude rate, we used propensity 
score weighting to obtain a weighted estimate ${ }^{22}$, since some maternal characteristics associated with higher rates of cesarean Sect. ${ }^{10}$ showed significant differences between the two models of care.

As secondary outcomes we used maternal outcomes (maternal death, Severe Maternal Morbidity, Maternal Near Miss, admission to an adult Intensive Care Unit, satisfaction with the care received) and perinatal outcomes (birth weight, gestational age at birth, asphyxia in the fifth minute of life, any neonatal complication, NICU admission, neonatal Near Miss, neonatal death and fetal death). For the measurement of Severe Maternal Morbidity (SMM), Maternal Near Miss (MNM) and Neonatal Near Miss (NNM), we used data from hospital records and the case definition criteria recommended by the World Health Organization ${ }^{23,24}$. To assess satisfaction with hospital care, we used data obtained during the interview and a validated scale for the Brazilian population ${ }^{25}$.

\section{Costs}

We used aggregate costs (total cost of hospitalization for women and newborns), from the perspective of the health care provider, within the adopted time horizon, that is, the length of the observed hospital stay. We did not apply discount rates and inflation rate adjustments due to the short time horizon.

In Brazilian private hospitals, there are different arrangements for payment of hospitalizations for childbirth care. The hospital included in this case study used the "package model". In this model, the health plan operator defines a basic package that covers the costs related to hospitalizations of vaginal births and cesarean sections without complications, to which are added the costs resulting from complications that may have occurred during hospitalization. The value of the basic package depends on the type of health plan, with a wide variation in the cost of hospitalization of women with vaginal or cesarean delivery without complications. Complication costs are not broken down into the total amount charged by the hospital to healthcare providers. However, the total cost reported, which we used in this analysis, includes the costs of the vaginal birth or cesarean section and all maternal and neonatal complications that occurred during hospitalization.

We assessed the mean cost and the range of the total cost of hospitalization of vaginal births and cesarean sections, with or without maternal and neonatal complications, for women in each type of model of care: the PPA and the standard of care model. The costs related to the implementation of PPA activities were not available.

\section{Cost-effectiveness analysis}

We calculated the incremental cost-effectiveness ratio (ICER) using the difference in the total cost of hospitalization and the difference in the proportion of cesarean sections in the two groups. The cost-effectiveness threshold of 18 to $71 \%$ of the Gross Domestic Product (GDP) per capita proposed for middle-high income countries was adopted ${ }^{26}$, corresponding to the values of US\$1,776.77 to US\$7,008.37 for the year 2017 (1US\$=R\$3.2).

\section{Scenario analysis}

We conducted univariate sensitivity analysis with the results being presented on a tornado diagram. We used the minimum and maximum costs observed in hospitalizations with and without maternal and neonatal complications in the two models of care. In the group assisted in the PPA model of care, we used variation in the probabilities of maternal and neonatal complications considering the minimum and maximum values observed, and variation in the probability of cesarean section, considering the theoretical plausibility of greater or lesser effects of the PPA model of care. We also used the hypothetical scenario of equal costs of hospitalizations for uncomplicated vaginal births and cesarean sections in both models of care.

We used the statistical package $\mathrm{R}$ for analyzes. 


\section{Results}

During the study period, 409 women were interviewed. Exclusions included women of Robson's groups 5 to 10 (164), Robson's group not classified (2), newborn with congenital malformation (2), gestational age equal to or greater than 42 weeks (2), women with HIV infection (1), or out-of-pocket payment of the hospitalization (2). Of the 238 included in the analysis, 84 were assisted in the PPA model of care and 154 in the standard of care model.

Women's mean age was 29 years old. Most women self-reported as mixed or white, had 11 to 14 years of study, belonged to the higher economic classes ${ }^{27}$, lived with a partner and had paid work. Only a fifth of women had a previous delivery, $55.9 \%$ preferred a vaginal delivery and $51.3 \%$ belonged to Robson's group 2 . A fifth of women had a risk pregnancy and $48.3 \%$ were overweight or obese. Women assisted in the standard of care model were older, more educated, belonged more to higher economic classes ( $A$ and B), had a higher proportion of risk pregnancy and overweight/obesity, and belonged to a greater proportion to Robson's group $2 \mathrm{~b}$. Women assisted in the PPA model of care had a greater preference for vaginal delivery and were mostly from Robson's group 1 . There were no statistically significant differences in relation to skin color, parity, marital status and paid work (Table 1). 
Table 1

- Demographic, social and obstetric characteristics of women according to the model of care. Rio de Janeiro, 2017.

\begin{tabular}{|c|c|c|c|c|c|c|c|}
\hline \multirow[t]{2}{*}{ Characteristic } & \multicolumn{2}{|c|}{$\begin{array}{l}\text { Total } \\
(\mathrm{N}=238)\end{array}$} & \multicolumn{2}{|c|}{$\begin{array}{l}\text { Standard } \\
\text { of care model }(N=154)\end{array}$} & \multicolumn{2}{|c|}{$\begin{array}{l}\text { PPA } \\
\text { model of care } \\
(\mathrm{N}=84)\end{array}$} & \multirow[t]{2}{*}{ p value } \\
\hline & $\mathrm{n}$ & $\%$ & $\mathrm{n}$ & $\%$ & $\mathbf{n}$ & $\%$ & \\
\hline \multicolumn{8}{|l|}{ Age (years) } \\
\hline$<20$ & 7 & 2.9 & 4 & 2.6 & 3 & 3.6 & $<0.001$ \\
\hline $20-34$ & 186 & 78.2 & 109 & 70.8 & 77 & 91.7 & \\
\hline 35 or more & 45 & 18.9 & 41 & 26.6 & 4 & 4.8 & \\
\hline \multicolumn{8}{|l|}{ Skin color } \\
\hline White & 78 & 32.8 & 54 & 35.1 & 24 & 28.6 & 0.307 \\
\hline Black & 45 & 18.9 & 25 & 16.2 & 20 & 23.8 & \\
\hline Mixed/Asian/Indigenous & 115 & 48.3 & 75 & 48.7 & 40 & 47.6 & \\
\hline \multicolumn{8}{|l|}{ Schooling (years) } \\
\hline 1 to 10 & 34 & 14.3 & 24 & 15.6 & 10 & 11.9 & 0.007 \\
\hline 11 to 14 & 136 & 57.1 & 76 & 49.4 & 60 & 71.4 & \\
\hline 15 or more & 52 & 21.8 & 40 & 26.0 & 12 & 14.3 & \\
\hline Postgraduate studies & 16 & 6.7 & 14 & 9.1 & 2 & 2.4 & \\
\hline \multicolumn{8}{|l|}{ Economic class } \\
\hline $\mathrm{D} / \mathrm{E}$ & 1 & 0.4 & 0 & 0.0 & 1 & 1.2 & 0.003 \\
\hline $\mathrm{C}$ & 70 & 29.4 & 36 & 23.4 & 34 & 40.5 & \\
\hline B & 156 & 65.5 & 107 & 69.5 & 49 & 58.3 & \\
\hline$A$ & 11 & 4.6 & 11 & 7.1 & 0 & 0.0 & \\
\hline Lives with partner & 205 & 86.1 & 136 & 88.3 & 69 & 82.1 & 0.188 \\
\hline Paid work & 183 & 76.9 & 118 & 76.6 & 65 & 77.4 & 0.895 \\
\hline \multicolumn{8}{|l|}{ Parity } \\
\hline 0 & 192 & 80.7 & 125 & 81.2 & 67 & 79.8 & 0.957 \\
\hline 1 to 2 & 43 & 18.1 & 27 & 17.5 & 16 & 19.0 & \\
\hline 3 or more & 3 & 1.3 & 2 & 1.3 & 1 & 1.2 & \\
\hline Preference for vaginal birth & 133 & 55.9 & 66 & 42.9 & 67 & 79.8 & $<0.001$ \\
\hline
\end{tabular}

PPA = Adequate Birth Project; $\mathrm{BMI}=$ Body Mass Index 


\begin{tabular}{|c|c|c|c|c|c|c|c|}
\hline \multirow[t]{2}{*}{ Characteristic } & \multicolumn{2}{|c|}{$\begin{array}{l}\text { Total } \\
(\mathrm{N}=238)\end{array}$} & \multicolumn{2}{|c|}{$\begin{array}{l}\text { Standard } \\
\text { of care model }(\mathrm{N}=154)\end{array}$} & \multicolumn{2}{|c|}{$\begin{array}{l}\text { PPA } \\
\text { model of care } \\
(\mathrm{N}=84)\end{array}$} & \multirow[t]{2}{*}{$p$ value } \\
\hline & $\mathbf{n}$ & $\%$ & $\mathbf{n}$ & $\%$ & $\mathbf{n}$ & $\%$ & \\
\hline 1 & 70 & 29.4 & 26 & 16.9 & 44 & 52.4 & $<0.001$ \\
\hline $2 a$ & 19 & 8.0 & 2 & 1.3 & 17 & 20.2 & \\
\hline $2 b$ & 103 & 43.3 & 97 & 63.0 & 6 & 7.1 & \\
\hline 3 & 19 & 8.0 & 7 & 4.5 & 12 & 14.3 & \\
\hline $4 a$ & 5 & 2.1 & 3 & 1.9 & 2 & 2.4 & \\
\hline $4 b$ & 22 & 9.2 & 19 & 12.3 & 3 & 3.6 & \\
\hline Risk pregnancy & 49 & 20.6 & 38 & 24.7 & 11 & 13.1 & 0.035 \\
\hline \multicolumn{8}{|c|}{ Pré-gestational BMI } \\
\hline Underweight & 9 & 3.8 & 6 & 3.9 & 3 & 3.6 & 0.023 \\
\hline Normal & 113 & 47.9 & 62 & 40.8 & 51 & 60.7 & \\
\hline Overweight & 68 & 28.8 & 48 & 31.6 & 20 & 23.8 & \\
\hline Obese & 46 & 19.5 & 36 & 23.7 & 10 & 11.9 & \\
\hline
\end{tabular}

The proportion of cesarean sections was three times higher in the standard of care model $(91.6 \% \mathrm{vs} 32.1 \%, p<0.001)$, with a small difference reduction in the weighted analysis ( $88.6 \%$ vs $31.7 \%, p<0.001)$. There were no maternal deaths. The differences in the proportions of SMM, MNM, admission to an adult ICU and satisfaction with childbirth and newborn care were not significant (Table 2). 
Table 2

- Maternal and neonatal outcomes according to the model of care. Rio de Janeiro, 2017.

\begin{tabular}{|c|c|c|c|c|c|c|c|}
\hline \multirow[t]{2}{*}{ Maternal and neonatal outcomes } & \multicolumn{2}{|c|}{$\begin{array}{l}\text { TOTAL } \\
(\mathrm{N}=238)\end{array}$} & \multicolumn{2}{|c|}{$\begin{array}{l}\text { Standard } \\
\text { of care model } \\
(\mathrm{N}=154)\end{array}$} & \multicolumn{2}{|c|}{$\begin{array}{l}\text { PPA } \\
\text { model of care } \\
(\mathrm{N}=84)\end{array}$} & \multirow[t]{2}{*}{$p$ value } \\
\hline & $\mathbf{N}$ & $\%$ & $\mathbf{n}$ & $\%$ & $\mathrm{n}$ & $\%$ & \\
\hline \multicolumn{8}{|l|}{ Maternal outcomes } \\
\hline \multicolumn{8}{|l|}{ Type of labor } \\
\hline Spontaneous & 89 & 37.4 & 33 & 21.4 & 56 & 66.7 & $<0.001$ \\
\hline Induced & 24 & 10.1 & 5 & 3.2 & 19 & 22.6 & \\
\hline Without labor & 125 & 52.5 & 116 & 75.3 & 9 & 10.7 & \\
\hline \multicolumn{8}{|l|}{ Type of birth } \\
\hline Vaginal & 70 & 29.4 & 13 & 8.4 & 57 & 67.9 & $<0.001$ \\
\hline Cesarean & 168 & 70.6 & 141 & 91.6 & 27 & 32.1 & \\
\hline weighted cesarean* & & & & 88.6 & & 31.7 & \\
\hline Severe Maternal Morbidity & 5 & 2.1 & 4 & 2.6 & 1 & 1.2 & 0.658 \\
\hline Maternal Near Miss & 1 & 0.4 & 1 & 0.7 & 0 & 0.0 & 1.000 \\
\hline Maternal death & 0 & - & 0 & - & 0 & - & \\
\hline Admission to Intensive Care Unit & 5 & 2.1 & 5 & 3.3 & 0 & 0.0 & 0.164 \\
\hline \multicolumn{8}{|c|}{ Maternal satisfaction with childbirth care } \\
\hline Clarity of information & 219 & 92.0 & 143 & 92.9 & 76 & 90.5 & 0.517 \\
\hline Respect & 227 & 95.4 & 147 & 95.5 & 80 & 95.2 & 0.939 \\
\hline Preserved intimacy & 231 & 97.1 & 151 & 98.1 & 80 & 95.2 & 0.220 \\
\hline Time available for questions & 212 & 89.1 & 141 & 91.6 & 71 & 84.5 & 0.096 \\
\hline Participation in the decision making & 217 & 91.2 & 144 & 93.5 & 73 & 86.9 & 0.086 \\
\hline Any type of violence & 6 & 2.5 & 3 & 1.9 & 3 & 3.6 & 0.668 \\
\hline Global satisfaction with childbirth & 228 & 95.8 & 148 & 96.1 & 80 & 95.2 & 0.745 \\
\hline Satisfaction with newborn care & 228 & 95.8 & 145 & 94.2 & 83 & 98.8 & 0.103 \\
\hline \multicolumn{8}{|l|}{ Neonatal outcomes } \\
\hline \multicolumn{8}{|l|}{ Birth weight } \\
\hline$<2.500 \mathrm{~g}$ & 7 & 3.0 & 5 & 3.3 & 2 & 2.4 & 0.225 \\
\hline 2500 to $3999 \mathrm{~g}$ & 218 & 92.8 & 144 & 94.1 & 74 & 90.2 & \\
\hline$\geq 4000 \mathrm{~g}$ & 10 & 4.3 & 4 & 2.6 & 6 & 7.3 & \\
\hline
\end{tabular}




\begin{tabular}{|c|c|c|c|c|c|c|c|}
\hline \multirow{2}{*}{$\begin{array}{l}\text { Maternal and neonatal outcomes } \\
37 \text { to } 38\end{array}$} & \multicolumn{2}{|c|}{$\begin{array}{l}\text { TOTAL } \\
(\mathbf{N}=\mathbf{2 3 8})\end{array}$} & \multicolumn{2}{|c|}{$\begin{array}{l}\text { Standard } \\
\text { of care model } \\
(N=154)\end{array}$} & \multicolumn{2}{|c|}{$\begin{array}{l}\text { PPA } \\
\text { model of care } \\
(\mathrm{N}=84)\end{array}$} & \multirow{2}{*}{$\begin{array}{l}\text { p value } \\
\\
<0.001\end{array}$} \\
\hline & 107 & 45.0 & 83 & 53.9 & 24 & 28.6 & \\
\hline Spontaneous ${ }^{\star \star}$ & 35 & 21.1 & 17 & 19.3 & 18 & 23.1 & 0.553 \\
\hline Induced & 72 & 35.5 & 66 & 48.2 & 6 & 9.1 & $<0.001$ \\
\hline 39 to 41 & 131 & 55.0 & 71 & 46.1 & 60 & 71.4 & $<0.001$ \\
\hline Apgar $<7$ in the 5 th minute of life & 2 & 0.9 & 1 & 0.7 & 1 & 1.2 & 1.000 \\
\hline Any neonatal complication & 30 & 12.6 & 16 & 10.4 & 14 & 16.7 & 0.163 \\
\hline Admission to NICU & 22 & 9.2 & 11 & 7.1 & 11 & 13.1 & 0.130 \\
\hline Neonatal Near Miss & 19 & 8.0 & 11 & 7.1 & 8 & 9.5 & 0.517 \\
\hline Stillbirth & 0 & - & 0 & - & 0 & - & \\
\hline Neonatal death & 0 & - & 0 & - & 0 & - & \\
\hline \multicolumn{8}{|c|}{$\begin{array}{l}\text { * weighted proportion of cesarean section using the propensity score. The variables "age", "years of study", "initial } \\
\text { preference for the type of childbirth" and "risk pregnancy" were used as explanatory variables for the logistic model } \\
\text { of the propensity score and the type of model of care as the outcome variable; **Spontaneous labor or rupture of } \\
\text { membranes. }\end{array}$} \\
\hline
\end{tabular}

There were no fetal or neonatal deaths. Of the total live births, $3 \%$ had low birth weight, $55 \%$ had gestational age between 39 and 41 weeks, $0.9 \%$ had moderate asphyxia in the 5 minute of life, $12.6 \%$ had some neonatal complication, $9.2 \%$ were admitted to the NICU and $8 \%$ were classified as NNM. A significantly higher proportion of early term births (gestational age 37-38 weeks) was observed in the standard of care model, with $79.5 \%$ of these through obstetric intervention (94.1\% in antepartum cesarean sections and 5.6\% in induced vaginal deliveries, data not shown in the table). The most frequent neonatal complication in both groups was transient tachypnea. Meconium aspiration syndrome was significantly more frequent in the PPA model of care (3.8\% in the PPA care model vs 0 in the standard of care model, $p=0.041$ ). There were no significant differences in the other neonatal outcomes (Table 2).

Women in the PPA model of care were more likely to have maternal complications after a vaginal delivery $(0.088)$ and less likely to have maternal complications after a cesarean Sect. (0.037) than women in the standard of care model ( 0.077 and 0.050 , respectively). The probability of neonatal complications was higher in women in the PPA model of care, both in vaginal delivery ( 0.105 vs 0.077$)$ and in caesarean section ( 0.185 vs 0.071$)$. The average cost of hospitalizations without complications was higher in women assisted in the PPA model of care, both for vaginal deliveries (US\$1,255.06 vs US\$1,015.74) and for cesarean sections (US\$1,294.18 vs US\$ 918.46). In hospitalizations with complications, the greatest differences were observed in vaginal births with neonatal complications, with the average cost in women assisted in the PPA model of care twice as high (US\$ 6,457.21 vs US\$2,924.62). Considering the primary outcome of the study, the PPA model of care resulted in a 56.9 percentage point reduction in the cesarean section probability and an increase in the total cost of US\$ $67,346.25$, which implies an incremental cost-effectiveness ratio of US\$ 1,183.59 per avoided cesarean section (Table 3). 
Table 3

- Probabilities of type of birth, complications and costs of hospitalization according to model of care.

\section{Parameters}

Standard of care model

$(n=154)$
PPA model of care

$(n=84)$

\section{Effectiveness}

Proportion of cesarean*

88.6

31.7

Probability of maternal complication after a vaginal birth

0.077

0.088

Probability of maternal complication after a cesarean

0.050

0.037

Probability of neonatal complication after a vaginal birth

0.077

0.105

Probability of neonatal complication after a cesarean

0.071

0.185

\section{Costs}

Vaginal birth without maternal complication

US\$ $1,015.74$

US\$ $1,255.06$

Vaginal birth with maternal complication

US\$ $1,464.53$

US\$ $1,279.54$

Cesarean without maternal complication

US\$ 918.46

US\$ $1,294.18$

Cesarean with maternal complication

US\$ 2,498.99

US\$ $1,874.70$

Vaginal birth without neonatal complication

US\$ 0.00

US\$ 0.00

Vaginal birth with neonatal complication

US\$ $2,924.62$

US\$ $6,457,21$

Cesarean without neonatal complication

US\$ 0.00

US\$ 0.00

Cesarean with neonatal complication

US\$ $4,785.56$

US\$ 4,527.87

Maternal hospitalization costs

US\$100,350.63

US\$ $127,573.84$

Neonatal hospitalization costs

US\$ $32,671.25$

US\$ 72,794.29

Total cost

US\$133,021.88

US\$ 200,368.13

\section{Cost-effectiveness analysis}

Difference in proportion of cesarean section

56.9

Difference in total cost

US\$67,346.25

Incremental Cost-Effectiveness Ratio (ICER)

$\mathrm{R} \$ 1,183.59 /$ avoided cesarean section

* weighted proportion of cesarean section using the propensity score. The variables "age", "years of study", "initial preference for the type of childbirth" and "risk pregnancy" were used as explanatory variables for the logistic model of the propensity score and the type of model of care as the outcome variable.

In the sensitivity analysis, the variation in the cost of cesarean section without maternal complication, applied to both groups, was the parameter with the greatest effect on ICER: when the cost of hospitalization is greater than US\$ $1,960.00$, women assisted in the PPA model of care have a 56.9 reduction in the proportion of cesarean sections at a lower cost. The increase in the cost of uncomplicated vaginal delivery in both groups and in the proportion of cesarean sections in the PPA group make the PPA model of care less cost-effective, while the reduction in the proportion of neonatal complications in vaginal births in the PPA group and the costs of these hospitalizations in both groups make it more cost-effective. The ICER was less sensitive to variations in the parameters of probability of maternal complications 
and the cost of these hospitalizations (Fig. 2). The use of the same average cost of hospitalization for vaginal births and cesarean sections without complications in both models of care, with an average cost variation of US\$ 625.00 to US\$2,500,00, resulted in a ICER of US\$ 641.20 to US\$579.38 per cesarean section avoided (data not shown in table).

\section{Figure 2: Univariate sensitivity analysis of parameters of cost and complications at the Incremental Cost-Effectiveness Ratio.}

\section{Discussion}

The PPA model of care was cost-effective in reducing cesarean sections in a private hospital located in the southeast of Brazil, the most developed region of the country. The Brazilian government does not recommend a threshold value for decisions on the incorporation of new technologies in the National Health System ${ }^{28}$. Therefore, we used a threshold value recommended for the evaluation of interventions in middle-income countries ${ }^{26}$. If we used the threshold of less than 1GDP per effectiveness recommended by the World Health Organization ${ }^{29}$, the PPA model of care would be very cost-effective.

The two parameters with the greatest influence on the cost-effectiveness results - the average cost of hospitalizations for vaginal births and cesarean sections without complications - are not related to the model of care. However, they are important parameters in the context of childbirth care in Brazilian private hospitals, since there are different arrangements for paying for hospitalizations in these hospitals. The inpatient package model, used in the hospital included in this case study, is the most common. In this model, the health plan operator defines the cost of hospitalizations for uncomplicated vaginal births and cesarean sections with a wide variation of this value according to the type of health plan. In this study, the average cost of uncomplicated vaginal birth and cesarean sections was higher in women assisted in the PPA model of care. Scenario analysis adopting the same average cost of hospitalization for uncomplicated vaginal and cesarean sections in the two models of care, using a wide range of values, resulted in lower ICER values for avoided cesarean section, making the PPA model of care even more cost- effective.

The other parameters found to influence the ICER were the proportion of cesarean sections and the proportion of neonatal complications, especially those related to vaginal deliveries. The greater the reduction in the rate of cesarean section in the PPA model of care, and the lower the occurrence of neonatal complications, the more cost-effective this model of care is. In a scenario of lower reduction in the cesarean section rate, reaching a rate of $50 \%$ in the PPA model of care group, the ICER would rise to US\$ 1,848.59 per avoided cesarean section. Regarding neonatal complications, the significantly higher proportion of meconium aspiration syndrome in the PPA group indicate that there are possibilities for improving the quality of childbirth care in this model of care.

The $2 / 3$ reduction in the cesarean section rate in the PPA model of care, in both crude and weighted analysis, is consistent with two previous studies that evaluated the effects of interventions to reduce cesarean sections in Brazilian private hospitals, which also found significantly lower rates of cesarean Sect. ${ }^{16,17}$. All these interventions have as common characteristics the implementation of models of care that promote physiological childbirth through adjustments in the hospital environment, implementation of clinical guidelines based on best clinical practices, promotion of the collaborative model of care between doctor and nurse-midwives during labor and childbirth care, and educational work with women.

The group of women assisted by the standard of care model had a much higher proportion of women in the Robson's groups $2 b$ and $4 b$, similar to a previous national study carried out in 2011-2012, where group $2 b$ was the most frequent group in Brazilian private hospitals ${ }^{30}$. In the PPA model of care, groups 1 and 2 a were the most frequent. Almost $90 \%$ of women in the PPA group presented labor, while in the standard of care model this value was lower than $25 \%$. Finally, in 
the PPA model of care the proportion of induced labor was seven times higher than that observed in the standard of care model, where the induction rate was less than $5 \%$. All these results suggest that the differences found between the two models of care are due to the actions implemented by the PPA. A more global change in the private sector is less likely, as women assisted by external teams showed the same pattern seen in private hospitals in $2011-2012$ 10,30. A $21 \%$ increase in the proportion of vaginal deliveries in the period 2014-2016 was also observed when comparing data from 5 hospitals participating in the PPA and 8 hospitals not participating in the city of São Paulo/Brazil ${ }^{12}$.

Serious negative outcomes, such as maternal, fetal and neonatal deaths, severe maternal morbidity and maternal and neonatal near miss, presented low frequency and with non-significant differences between the two models of care. However, women in the standard of care model presented almost twice the proportion of early term births, most of them associated with antepartum cesarean sections. It is estimated that, in Brazil, about $35 \%$ of live births are early term ${ }^{31}$, corresponding to more than 300 thousand early term births per year, with a higher prevalence in places with cesarean rates above $80 \%{ }^{32}$. In a previous nationwide Brazilian study, early term births, especially non-spontaneous births, were associated with several negative outcomes, such as oxygen use, neonatal ICU admission and neonatal death ${ }^{31}$.

This study has some limitations. As we used data from only one hospital, we cannot extrapolate the observed results to the set of hospitals participating in the PPA, as the local contextual characteristics may have affected the implementation of the recommended actions and the observed effects ${ }^{33}$. In addition, the study is probably underpowered to detect differences in less frequent results due to the small sample size.

Costs related to the implementation of the PPA were not included, as they were not available. Hospital managers, health plan operators and the project coordination should consider these expenses when deciding to implement the PPA in new maternity services.

Finally, we used a short time horizon. There is evidence of negative medium and long-term effects associated with cesarean section, both for women and newborns ${ }^{3,4}$. There is also evidence of more neonatal complications after hospital discharge in early term births, more frequently observed in the standard of care model.

\section{Conclusion}

The PPA model of care was cost-effective in reducing cesarean sections in women in Robson's group 1 to 4 assisted in a Brazilian private hospital, with a higher occurrence of women in labor, with induction of labor, and a lower proportion of early term births.

In this hospital, the cost of uncomplicated vaginal births and cesarean sections was the parameter with the greatest impact on the cost-effectiveness ratio of the PPA model of care. Greater reductions in the rate of cesarean sections and neonatal complications, especially in vaginal births, would also lead to more favorable economic results.

New studies in Brazilian hospitals located in other macro-regions, in private hospitals not belonging to health operators, and with the inclusion of women with previous cesarean section, are necessary to expand knowledge on the subject and to base future strategies for reducing cesarean sections in public and private hospitals in the country.

\section{Abbreviations}

ANS - National Supplementary Health Agency

BMI - Body Mass Index

Page 13/18 
ICU - Intensive Care Unit

IHI - Institute for Health Improvement

MNM - Maternal Near Miss

NICU - Neonatal Intensive Care Unit

NNM - Neonatal Near Miss

PPA - Adequate Childbirth Project

SMM - Severe Maternal Morbidity

WHO - World Health Organization

\section{Declarations}

\section{Ethics approval and consent to participate}

The "Healthy Birth" study was approved by the research ethics committee of the Escola Nacional de Saúde Pública Sérgio Arouca/Fiocruz (CAAE research protocol: 1.761.027, approved on January 16, 2017). All women received and signed the Free and Informed Consent Form prior to the interview and all precautions were taken to maintain the confidentiality of the information.

\section{Consent for publication}

Not applicable

\section{Availability of data and materials}

All data generated or analysed during this study are included in this published article.

\section{Competing interests}

The authors declare that they have no competing interests.

\section{Funding}

This work was supported by fundings from Centro Nacional de Desenvolvimento Científico e Tecnológico (CNPq) and Bill \& Melinda Gates Foundation, Edital MCTI/CNPq/MS/SCTIE/Decit/Fundação Bill e Melinda Gates N47/2014. The funders had no influence in the identification, design, conduct, and reporting of the analysis.

\section{Authors' contributions}

RMSMD was responsible for the conception and design of the work, data analysis, discussion of results and elaboration of the manuscript; PML contributed to the analysis and interpretation of data, discussion of results and elaboration of manuscript; BVSA contributed to data analysis and approval of the final version of the manuscript; JAT contributed to 
the review and approval of the final version of the manuscript; MCL was the researcher responsible for the "Healty Birth" study design and contributed to the review and approval of the final version of the manuscript.

\section{Acknowledgements}

Not applicable.

\section{References}

1. Souza JP, Gülmezoglu A, Lumbiganon P, Laopaiboon M, Carroli G, Fawole B, et al. Caesarean Section Without Medical Indications Is Associated With an Increased Risk of Adverse Short-Term Maternal Outcomes: The 20042008 WHO Global Survey on Maternal and Perinatal Health. BMC Med. 2010;10:8:71.

2. Mascarello KC, Horta BL, Silveira MF. Maternal complications and cesarean section without indication: systematic review and meta-analysis. Rev Saude Publica. 2017;51:105.

3. Sandall J, Tribe RM, Avery L, Mola G, Visser GH, Homer CS, et al. Short-term and long-term effects of caesarean section on the health of women and children. Lancet. 2018;392(10155):1349-57.

4. Keag OE, Norman J, Stock S. Long-term risks and benefits associated with cesarean delivery for mother, baby, and subsequent pregnancies: Systematic review and meta-analysis. PLoS Med. 2018;15(1):e1002494.

5. Sobhy S, Arroyo-Manzano D, Murugesu N, Karthikeyan G, Kumar V, Kaur I, et al. Maternal and perinatal mortality and complications associated with caesarean section in low-income and middle-income countries: a systematic review and meta-analysis. Lancet. 2019;393(10184):1973-82.

6. Ye J, Betrán AP, Guerrero Vela M, Souza JP, Zhang J. Searching for the optimal rate of medically necessary cesarean delivery. Birth. 2014;41:237-44.

7. Souza JP, Betran AP, Dumont A, de Mucio B, Gibbs Pickens CM, Deneux-Tharaux C, et al. A global reference for caesarean section rates (C-Model): a multicountry cross-sectional study. BJOG. 2016;123(3):427-36.

8. Brasil M, Saúde. Secretaria de Ciência, Tecnologia e Insumos Estratégicos, Comissão Nacional de Incorporação de Tecnologias no SUS. Diretrizes de Atenção à Gestante: a operação cesariana. Brasília, DF: Conitec, 2016. http://conitec.gov.br/images/Relatorios/2016/Relatorio_Diretrizes-Cesariana_final.pdf. Accessed on May 25, 2020.

9. Rebelo F, Rocha CMM, Cortes TR, Dutra CL, Kac G. High cesarean prevalence in a national population-based study in Brazil: the role of private practice. Acta Obstet Gynecol Scand. 2010;89:903-8.

10. Domingues RMSM, Dias MAB, Nakamura-Pereira M, Torres JA, D’Orsi E, Pereira APE, et al. Process of decisionmaking regarding the mode of birth in Brazil: from the initial preference of women to the final mode of birth. Cad Saude Publica. 2014;30(supl 1):1-16.

11. Agência Nacional de Saúde Suplementar. Parto Adequado. http://www.ans.gov.br/gestao-em-saude/partoadequado. Accessed on June 27, 2020.

12. Borem P, de Cássia Sanchez R, Torres J, Delgado P, Petenate AJ, Peres D, et al. A Quality Improvement Initiative to Increase the Frequency of Vaginal Delivery in Brazilian Hospitals. Obstet Gynecol. 2020;135(2):415-25.

13. The Breakthrough Series: IHI's Collaborative Model for Achieving Breakthrough Improvement. IHI Innovation Series white paper. Boston: Institute for Healthcare Improvement; 2003. http://www.ihi.org/resources/

Pages/IHIWhitePapers/TheBreakthroughSeriesIHIsCollaborativeModelforAchievingBreakthroughlmprovement.aspx. Accessed on June 2nd, 2019.

14. Torres JA, Leal MDC, Domingues RMSM, Esteves-Pereira AP, Nakano AR, Gomes ML, et al. Evaluation of a quality improvement intervention for labour and birth care in Brazilian private hospitals: a protocol. Reprod Health. 
2018;15(1):194.

15. Chaillet N, Dumont A. Evidence-based strategies for reducing cesarean section rates: a meta-analysis. Birth. 2007;34:53-64.

16. Torres JA, Domingues RMSM, Sandall J, Hartz ZMA, Gama SGN, Theme-Filha MM, et al. Caesarean section and neonatal outcomes in private hospitals in Brazil: comparative study of two different perinatal models of care. Cad Saude Publica. 2014;30(supl 1):220-31. 23.

17. Borem P, Ferreira JBB, da Silva UJ, Valério Júnior J, Orlanda CMB. Increasing the percentage of vaginal birth in the private sector in Brazil through the redesign of care model. Rev Bras Ginecol Obstet. 2015;37:446-54.

18. Gama SG, Viellas EF, Torres JA, Bastos MH, Brüggemann OM, Theme Filha MM, et al. Labor and birth care by nurse with midwifery skills in Brazil. Reprod Health. 2016;17(Suppl 3):123. 13(.

19. Leal MC, Pereira APE, Domingues RMSM, Theme-Filha MM, Dias MAB, Nakamura-Pereira M, et al. Obstetric interventions during labor and childbirth in Brazilian low-risk women. Cad Saude Publica. 2014;30(supl 1):17-32.

20. Robson MS. Can we reduce the caesarean section rate? Best Pract Res Clin Obstet Gynaecol. 2001;15(1):179-94.

21. Vogel JP, Betrán AP, Vindevoghel N, Souza JP, Torloni MR, Zhang J, et al. Use of the Robson Classification to Assess Caesarean Section Trends in 21 Countries: A Secondary Analysis of Two WHO Multicountry Surveys. Lancet Glob Health. 2015;3(5):e260-70.

22. Paes AT. Uso de escores de propensão para corrigir diferenças entre grupos. Educ Contin Saúde einstein. 2012;10(3):103-4.

23. Say L, Souza JP, Pattinson RC. Maternal near miss - towards a standard tool for monitoring quality of maternal health care. Best Pract Res Clin Obstet Gynaecol. 2009;23:287-96.

24. Pileggi-Castro C, Camelo JS Jr, Perdoná GC, Mussi-Pinhata MM, Cecatti JG, Mori R, et al. Development of criteria for identifying neonatal near-miss cases: analysis of two WHO multicountry cross-sectional studies. BJOG. 2014;121(Suppl 1):110-8.

25. Costa DDO, Ribeiro VS, Ribeiro MRC, Esteves-Pereira AP, Sá LGC, Cruz JADS, et al. Psychometric properties of the hospital birth satisfaction scale: Birth in Brazil survey. Cad Saude Publica. 2019;35(8):e00154918.

26. Woods B, Revill P, Sculpher M, Claxton K. Country-level cost-effectiveness thresholds: initial estimates and the need for further research. Value Health. 2016;19(8):929-35.

27. Associação Brasileira de Empresas de Pesquisa. Critério Brasil de classificação econômica. http://www.abep.org/criterio-brasil. Accessed on May 25, 2020.

28. Brasil. Ministério da Saúde. Secretaria de Ciência, Tecnologia e Insumos Estratégicos. Departamento de Ciência e Tecnologia. Diretrizes metodológicas: Diretriz de Avaliação Econômica. 2. ed. Brasília: Ministério da Saúde, 2014. 132p. http://bvsms.saude.gov.br/bvs/publicacoes/diretrizes_metodologicas_diretriz_avaliacao_economica.pdf. Accessed on May 14, 2020.

29. Macroeconomics and health: investing in health for economic development. Report of the Commission on Macroeconomics and Health. Geneva: World Health Organization; 2001. http://apps.who.int/iris/bitstream/10665/42435/1/924154550X.pdf. Accessed on May 15, 2020.

30. Nakamura-Pereira M, do Carmo Leal M, Esteves-Pereira AP, Domingues RM, Torres JA, Dias MA, et al. Use of Robson classification to assess cesarean section rate in Brazil: the role of source of payment for childbirth. Reprod Health. 2016;13(Suppl 3):128.

31. Leal MDC, Esteves-Pereira AP, Nakamura-Pereira M, Domingues RMSM, Dias MAB, Moreira ME, et al. Burden of early-term birth on adverse infant outcomes: a population-based cohort study in Brazil. BMJ Open.

2017;7(12):e017789. 
32. Barros FC, Rabello Neto DL, Villar J, Kennedy SH, Silveira MF, Diaz-Rossello JL, et al. Caesarean sections and the prevalence of preterm and early-term births in Brazil: secondary analyses of national birth registration. BMJ Open. 2018;8(8):e021538.

33. Domingues RMSM, Torres JA, Leal MC, Hartz Z. Fatores contextuais na análise da implantação de uma intervenção multifacetada em hospitais privados brasileiros: reflexões iniciais da pesquisa avaliativa "Nascer Saudável". Anais do IHMT 2019;Supl 1:S47-S55.

\section{Figures}

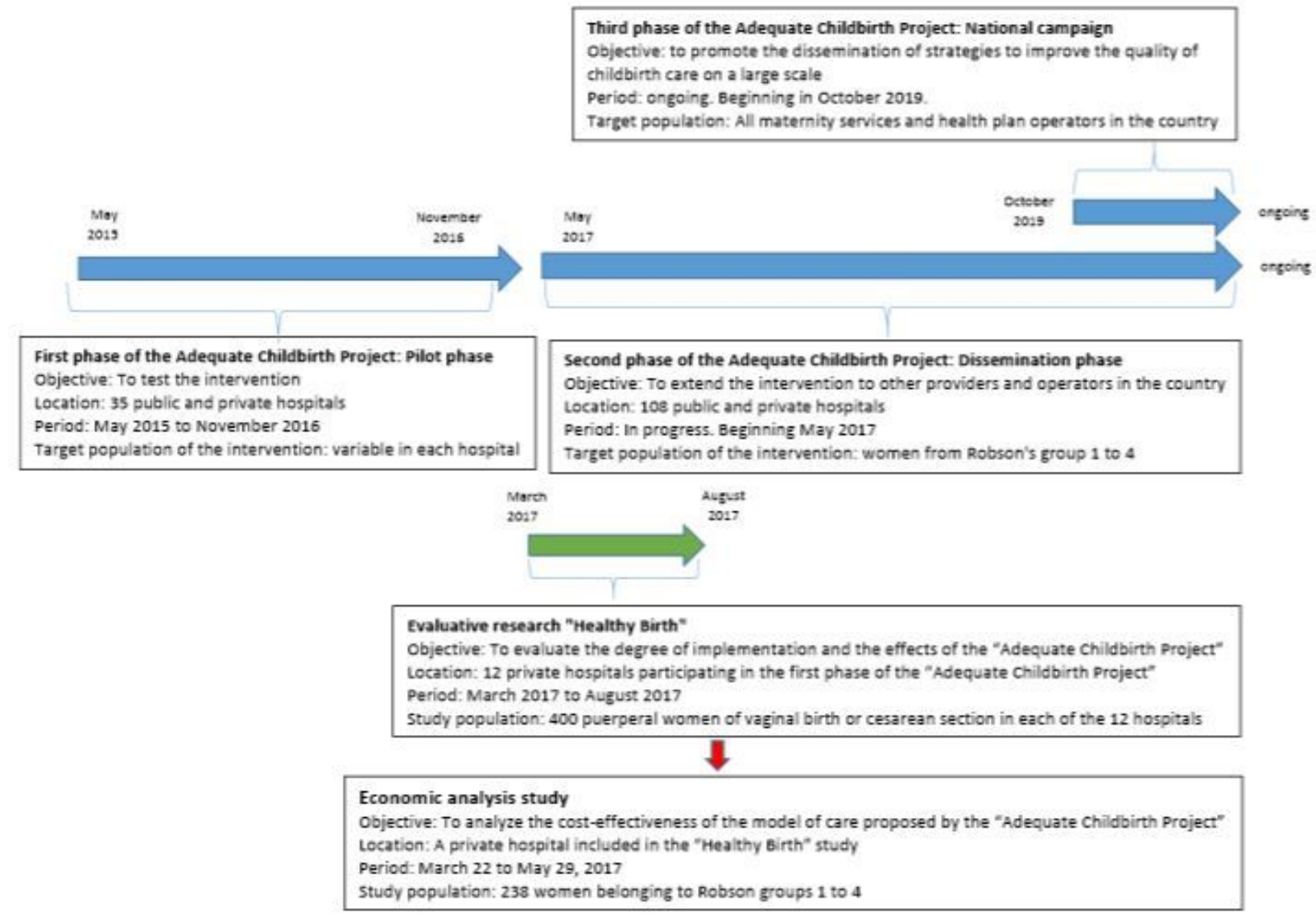

Figure 1

Description of the "Adequate Childbirth Project", the evaluative research "Healthy Birth "and the economic analysis study 


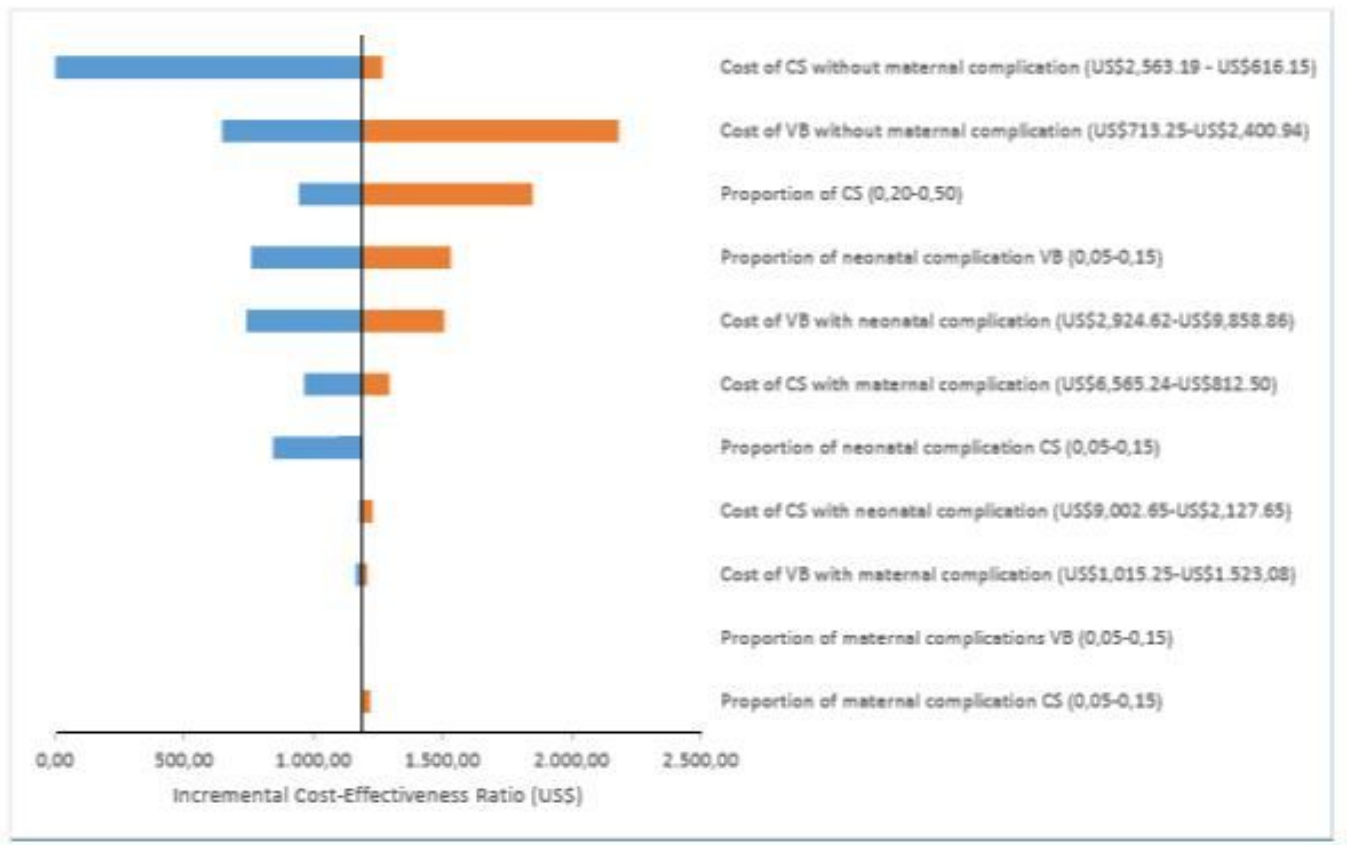

Figure 2

Univariate sensitivity analysis of parameters of cost and complications at the Incremental Cost-Effectiveness Ratio.

\section{Supplementary Files}

This is a list of supplementary files associated with this preprint. Click to download.

- CHEERSchecklist.docx 